УДК [330.341.2+330.341.4](476)

\title{
ТРАНСФЕР ТЕХНОЛОГИЙ КАК ЭКОНОМИЧЕСКИЙ РЕСУРС
}

\author{
Л.П. ВАСЮЧЕНОК \\ к.э.н., доцент кафедры «Экономика и право» \\ Белорусского национального технического университета, г. Минск
}

\begin{abstract}
Аннотация
Статья посвящена исследованию особенностей трансфера технологий как экономического ресурса. Показано, что специфика трансфера технологий (TT) состоит в особенностях предмета трансфера - технологий, имеющих товарную и нетоварную составляющую (явное и неявное знание), особенностях субъектов TT, предполагающих как минимум трехкратную полную смену команд доноров и реципиентов технологий, и особенных формах трансфера, из которых наиболее предпочтительным для Республики Беларусь является инновационный кластер, включающий в себя больше частей цепочки ценности, чем другие формы TT.
\end{abstract}

Abstract

The article investigates the features of technology transfer as an economic resource. It is shown that the specific of technology transfer (TT) consists of specialties of subject of transfer - technologies of commodity and non-commodity component (implicit and explicit knowledge), features of subjects of TT guessing at least three times a complete change of donors teams and recipients of technology, and special forms of transfer, of which the most preferred for the Republic of Belarus is the innovation cluster, which includes much more parts of the value chain than other forms of TT.

\section{ВВЕДЕНИЕ}

Вхождение мирового сообщества в новое тысячелетие обусловлено структурными и институциональными преобразованиями экономики, новыми драйвер факторами социально-экономического развития, которые послужили основой становления качественно нового явления - трансфера технологий (ТT). Большинство стран мира активно участвуют в трансфере технологий, в том числе международном, развитые страны занимают лидирующие позиции на мировом рынке по объему потребляемых иностранных результатов научно-технической деятельности, по величине экспортных технологических поступлений, составляющих значительную долю в структуре их платежного баланса. Для стран с переходной экономикой активное включение в процесс трансфера технологий имеет особую актуальность в связи с необходимостью повышения конкурентоспособности. В Республике Беларусь трансфер технологий, в том числе международный, является одним из векторов инновационного развития национальной экономики. Исследование теоретических основ трансфера технологий, изучение особенностей международного трансфера и тенденций его развития, разработка и практическая реализация рекомендаций по совершенствованию модели участия Республики Беларусь в международном трансфере технологий - круг вопросов, нуждающихся в систематическом исследовании.

\section{РЕЗУЛЬТАТЫ И ИХ ОБСУЖДЕНИЕ}

Понятие «трансфер технологий» появилось в русскоязычной литературе недавно и напрямую связано с переориентацией на рыночные отношения в большинстве сфер хозяйственной жизни. Часто его употребляют вместе с другим понятием - «коммерциализация технологий», хотя смысловое содержание этих понятий не совпадает.

Англоязычное слово «трансфер» заместило термин «внедрение», которым административно-командная система наделила процесс претворения в жизнь инновационного предложения. Однако это не простое замещение, а существенное преобразование смысла процесса. Вместо насильственного «внедрения» (предполагающего активное или пассивное сопротивление среды, в которую производится это «внедрение» чего-то инородного) «трансфер» предполагает не только передачу информации о новшестве, но и ее освоение при активном позитивном участии и источника этой информации (например, автора изобретения), и реципиента, приемника информации о новой технологии, и конечного пользователя продукта, производимого с помощью этой технологии. Основной акцент при трансфере технологии делается не столько на технологии как таковой, сколько на субъектах - участниках этого процесса.

Иными словами, трансфер - это путь, который должна пройти идея ученого или изобретателя в любой сфере деятельности, чтобы превратиться в осязаемый успех для автора и для общества. Главное здесь - кто и как должен сопровождать эту идею на каждом этапе ее сложного пути, какие преграды и подводные камни встретятся, кого привлечь при преодолении каждого из барьеров. Как отмечают практические участники трансфера технологий, одна из главных трудностей состоит в том, чтобы убедить автора изобретательской идеи, что довести ее до конечного продукта он самостоятельно не сможет практически никогда, что идея должна пройти цепочку «теоретик-исследователь -практик-исследователь -- технолог -- технолог-производственник -- маркетолог -- продавец», вовлекая в это движение

\footnotetext{
* Работа подготовлена в рамках выполнения Договора с БРФФИ № Г14РА-002 от 16 июня 2014 г. «Методология развития технологических трансфертов между Беларусью и Румынией в контексте формирования промышленных кластеров»
} 
и государственные учреждения, и прессу, и банки, и вспомогательные производства. Именно этот процесс и называется «трансфер технологий».

Понятие «коммерциализация технологии» предполагает обязательное коммерческое использование информации о технологии, т.е. использование с извлечением выгоды. Чаще всего эта выгода измеряется в конкретных денежных единицах непосредственно, реже - опосредованно, через, например, увеличение эффективности другой технологии. Но деньги в этих расчетах присутствуют всегда и являются определяющим критерием успешности процесса. В то же время вопрос о том, кто, какой субъект осуществляет непосредственное использование технологии, при коммерциализации не является первостепенным, и в частности, коммерциализацией нередко пытается заняться сам автор, первоисточник новой технологии (физическое лицо или организация). Различия между трансфером и коммерциализацией следующие: а) коммерциализация технологии предполагает обязательное получение прибыли и не обязательно связано с подключением третьих лиц (кроме источника технологии и конечного пользователя); б) трансфер технологии предполагает обязательную передачу технологии реципиенту, который и осушествляет ее промышленное освоение, но это не обязательно связано с извлечением прибыли как источником технологии, так и ее реципиентом (что относится, например, к экологическим технологиям).

Трансфер технологий заинтересовал деловую общественность и руководство республики только после того, как был избран рыночный курс развития экономики. Но практики социалистического затратного механизма хозяйствования до сих пор накладывают специфический оттенок на отношение к этому процессу. В рамках этого механизма изобретение принадлежало государству, которое декларировало законодательно свое право и свою обязанность довести изобретение до освоения народным хозяйством. Процедура же этого внедрения была настолько обессмыслена с экономической точки зрения, что только при крайне редком стечении обстоятельств новшество доводилось до такого состояния, когда можно было считать экономический эффект от его освоения. Поэтому говорить о трансфере технологий (в истинном смысле этого словосочетания) в социалистическом обществе было бы некорректно. Впрочем, называть такое «внедрение» коммерциализацией тоже едва ли правильно. Прежде всего потому, что метод расчета его экономического эффекта был весьма своеобразным. Если по старой технологии затраты составляли N1 рублей на единицу продукции, а по новой - N2 рублей, то годовой экономический эффект равен M*(N1-N2) рублей, где M - годовой объем выпуска продукции. Но если изобретение внедрялось до того, как старая технология была запущена в производство, или если старой технологии вообще не было, т.е. появилось пионерное изобретение, то экономический эффект (и вознаграждение изобретателя) были равны нулю. Кроме того, и «коммерция» была понятием порицаемым.

В настоящее время ситуация несколько изменилась, но до принятого в современной деловой практике понимания роли и смысла трансфера и коммерциализации технологий еще достаточно далеко. Современный бизнесмен прекрасно понимает, что единственным удачным изобретением, доведенным до массового производства, он может обеспечить процветание своей фирме на долгие годы, поэтому он активно ищет такое изобретение, вкладывает деньги в изобретение и в изобретателя (за соответствующую долю в будущем предприятии). Однако он понимает и то, что это вложение средств - долгосрочное, это не мелкий торговый бизнес с длительностью «производственного цикла» в недели, а многостадийный и тщательно планируемый процесс, сочетающий и научное исследование технологии, и ее масштабирование и оптимизацию, и маркетинг, и заботы о сбытовой сети, и многое другое. Менталитет же отечественных бизнесменов в большинстве случаев далек от такого скрупулезного подхода и поиска революционных технологий или продуктов, да и с финальной частью процесса (маркетинг и сбыт) пока у отечественного бизнеса отношения сложные. Представители зарубежных фирм, приобретающие у нас перспективные разработки, были бы и рады организовать производство по этим разработкам здесь же, но, с одной стороны, легионы чиновничества ставят столько препятствий, что никакого терпения все это понять и пережить не хватает, а с другой стороны, наличная производственная база и ее пользователи настолько озабочены перманентным форс-мажором, что найти с ними общий язык преуспевающему иностранному бизнесмену непросто. Поэтому оптимальным местом освоения перспективных новшеств и сейчас по-прежнему является отнюдь не наша страна, в связи с чем придется затронуть особенности международного трансфера технологий.

Характеристика трансфера технологий как экономического ресурса предполагает не только выявление экономических субъектов данного процесса, на которых было указано выше, но и определение предмета их отношений, во многом определяющего способы и формы их взаимодействия. И здесь далеко не все так просто, как может показаться на первый взгляд. В трансфере технологий предметом отношений достаточно широкого круга участников по определению является технология. Но как отмечают исследователи, «принято считать, что «технология» - весьма абстрактное понятие, плохо поддающееся как эмпирическому наблюдению, так и количественной оценке»[1]. Констатируя наличие множества определений, авторы первым приводят определение электронной энциклопедии: «Технология-в широком смысле-совокупность методов, процессов и материалов, используемых в какой-либо отрасли деятельности, а также научное описание способов технического производства; в узком-комплекс организационных мер, операций и приемов, направленных на изготовление, обслуживание, ремонт и/или эксплуатацию изделия с номинальным качеством и оптимальными затратами и обусловленных текущим уровнем развития науки, техники и общества в целом». Процесс передачи (обмена, торговли) технологий носит название трансфера технологий, при этом, если он осуществляется между странами, - международного трансфера технологий». Но наиболее удачным они считают следующее. «Международный трансфер технологий (international technology transfer) определяется как совокупность экономических отношений между фирмами различных стран в области использования зарубежных научно-технических достижений. При этом понятие «технология» включает в себя, с одной стороны, - собственно технологию (disembodied/dissembled technology - бестелесную технологию), понимаемую как набор конструктивных решений, ме- 
тодов и процессов, с другой - материализованную технологию (еmbodied technology), то есть технологию, воплощенную в машинах, оборудовании и т.п. Соответственно, предметом трансфера могут выступать оба типа объектов, - как совместно, так и в отдельности»[2]. Развитие данного подхода предлагает Е. Бертош, формулируя концепцию технологического пакета как непосредственного объекта трансфера. Технологический пакет трактуется автором как совокупность материальных и нематериальных объектов (услуг), набор которых зависит от уровня технологического развития субъектов международного трансфера технологий [3].

Один из наиболее универсальных вариантов определения технологии был предложен в 1999 году Винодом Кумаром (Университет Карлтон, Канада) и его коллегами. По их мнению, технология включает в себя два первичных компонента: 1) физический, то есть такие элементы, как произведенные продукты, оборудование, инструменты, чертежи и схемы, производственные процессы; 2) информационный - это ноу-хау в сфере менеджмента, маркетинга, контроля качества продукции, система обеспечения ее послепродажного обслуживания, а также специально обученная рабочая сила и техперсонал [4]. Что же касается производного термина «трансфер технологий», то под ним понимают процесс передачи (перемещения) из одного места в другое как физического, так и информационного компонента.

Многие исследователи отмечают, что информационный компонент технологии (ноу-хау) в отличие от физического (собственно продукта), как правило, не поддается простому воспроизведению, то есть ее эффективный трансфер — передача от непосредственного разработчика конечному пользователю — сопряжен с необходимостью получения последним не только явно выраженного знания об общих принципах действия технологии, но и целого комплекса сопутствующей информации - того, что в философии науки принято называть неявным знанием (tacit knowledge).

Концепция неявного знания была разработана Майклом Поланьи в 50-е годы XX века, но долго оставалась теоретической игрушкой. Согласно Поланьи, неявное знание - это набор личностных, некодифицированных знаний, вплетенных в искусство экспериментирования и теоретические навыки ученых (и технологов), которые передаются исключительно неформальными способами и в непосредственных человеческих контактах. В случае с ТТ данный набор «тайных знаний», которыми обладают ее создатели (в нашем контексте это страна или фирма - донор технологии), во многом определяет то, насколько полноценным окажется в итоге процесс передачи тех или иных технических знаний и решений. Так, британский экономист Ричард Ли-Хуа подчеркивает, что реальный ТТ невозможен без параллельного трансфера знаний, поскольку именно знания (технические, экспертные решения, опыт, отработанные на практике навыки и схемы работы с конкретной технологией), и прежде всего неявные, — ключевой фактор, обеспечивающий контроль за технологиями в целом. Более того, эффективный ТТ фактически недостижим там, где существует значительный разрыв между уровнем экономического развития передающей и принимающей сторон.

Наличие скрытой составляющей технологического знания, как стало понятно сегодня, — ключевой момент проблематики трансфера технологий [4]. Реально обладающие неявным знанием экономические агенты (фирмы, научно-исследовательские учреждения, отдельные индивидуумы-изобретатели и т. д.) при прочих равных условиях отнюдь не стремятся делиться им, прекрасно отдавая себе отчет в том, что любая инновационная технология предоставляет конкурентные преимущества на рынке. Кроме того, сохраняя до поры до времени в тайне различные неявные элементы новой технологии, ее владельцы тем самым значительно затрудняют потенциальным конкурентам процесс ее быстрого копирования и возможного улучшения. В то же время, по мере того как абсорбированная рынком новая технология переходит из ранней стадии в более зрелую, упорное воздержание ее владельцев от передачи вовне «полного пакета» чревато потерей возможности получения дополнительной прибыли (за счет оказания профессионального комплекса услуг по техподдержке, эксплуатационному обслуживанию, ремонту и т. п.). Эта технологическая дихотомия есть прямое отражение стандартного процесса жизненного цикла технологии: когда последняя уже не дает владельцу возможность снимать сливки с рынка, наиболее рациональным решением становится ее скорейшая продажа (через лицензирование и другие формы трансфера).

Предметом трансфера может быть и конкретная вещь (например, микропроцессор нового типа), который сам по себе технологией не является. Однако и в этом случае с инновационным предметом обязательно связано то или иное умение, искусство, та или иная технология (либо технология производства, либо технология применения или осуществления), поэтому понятие «трансфер технологии» всегда несет вполне определенный смысл. Этот смысл становится более очевидным, если учесть, что наиболее надежным способом защиты любого объекта и любой технологии как источника технологической ренты (дохода, превышающего средний за счет использования новой технологии) является не патент, а так называемое «нераскрываемое ноу-хау», «неявное знание», которым в полной мере владеет только источник инновационного предложения. Так что в данной работе использование понятия «технология» ближе всего не к устоявшейся производственной трактовке, а к его прямому переводу.

Если обратиться к самому определению термина технология, к его изначальному значению (техно - мастерство, искусство; логос - наука), то цель технологии заключается в том, чтобы разложить на составляющие элементы и сделать устойчиво воспроизводимым процесс достижения какого-либо результата. Техника - общее название различных приспособлений, механизмов и устройств, не существующих в природе и изготовляемых человеком. Технология - способ преобразования исходных сырья, полуфабрикатов или данных в конечный продукт с заданными свойствами. Понятие технологии, которое используется в работе, опирается на трактовку, предложенную М. В. Белоусенко в работе «Общая теория экономической организации: организационная эволюция индустриальной экономики». Согласно автору, производство индустриального типа - это, прежде всего, применение искусственных материалов и орудий труда, и именно они задают последовательность и методы собственного использования (хотя и в широких пределах). Поэтому под технологиями понимается совокупность технической системы, приемов ее применения, знаний и опыта (профессий, социальных ролей), необходимых для ее эксплуатации. Техническая система представляет 
собой инструменты или, точнее, средства производства, используемые для превращения исходного материала в продукт, и включает: (1) орудия труда, (2) передаточный механизм, (3) источник энергии, (4) коммуникационные устройства, (5) вспомогательные устройства, (6) контрольно-логические элементы. Такое определение избавляет от необходимости делать оговорки в процессе употребления категории «технология» об объективном, заданном технической системой характере приемов и методов использования средств и предметов производства, и в то же время указывать на субъективный элемент технологий - человека, выполняющего эти приемы. Данное определение объединяет человека и технические элементы технологического комплекса, фактически уже показывает их неразрывную связь и позволяет протянуть логическую нить от производства, понимаемого как физическая трансформация ресурсов в продукт, к социальным отношениям, в которых оно протекает. [5].

Трансфер технологии предполагает участие в этом процессе нескольких функционально разных субъектов. Начинается все со случая, со случайного открытия, причем в области, далекой от прагматических процессов типа технологий, продуктов, оборудования - в области фундаментальных исследований. С обнаружения непонятного явления и попытки разобраться в его причинах начинается длинная дорога к технологии. Происходит открытие, точнее, «открытие-случайность». Его делают не академики (академиками они станут потом), но дальше уже профессиональными научными коллективами разрабатываются гипотеза за гипотезой, ученые изучают новое явление, пытаясь понять, в чем же его причина. Гипотеза становится теорией, общепризнанным законом, если она может не только объяснить открытое явление, но и предсказать другие явления, никем не наблюдавшиеся. Окончательным судьей в споре гипотез является эксперимент, результаты которого можно интерпретировать с помощью только одной из предложенных гипотез. Когда такой эксперимент найден, поставлен и убедительно подтвердил гипотезу, рождается новый закон. Дальнейшая работа фундаментальной науки состоит в новых подтверждениях закона (рутинная работа), а также в определении границ его актуальности. Эстафета исследований теперь переходит к ученым-прикладникам.

Представители фундаментальной науки редко и не слишком охотно общаются с представителями прикладной науки, поэтому последним приходится самостоятельно отслеживать появление нового закона и пытаться нащупать, что же можно извлечь из нового закона такого, что могло бы стать полезным и интересным для практики, для технологии. Поиск открытий (не зависящих от человека законов) сменяется поиском изобретений (созданных человеком) новых явлений, эффектов, процессов и предметов. Здесь решаются практически те же задачи, что и при рутинных исследованиях фундаментальной науки. Но цель исследований здесь - не подтверждение закона, а поиск подходов, операций, способов, позволяющих предположительно достичь новых практически важных результатов. Выкристаллизовывается изобретение на новый способ, устройство, применение. Идея изобретения претворяется в лабораторный эксперимент конкретной технологической направленности, целью которого является получение полезного результата. Когда результат получен, становится понятно, что разработан продукт, имеющий коммерческую перспективу, надо начинать работу по его будущему продвижению на рынок. Но это уже следующий уровень трансфера технологии.

Прообраз новой технологии родился на лабораторном стенде, собранном из подручных средств. Здесь же продолжается работа с единичными образцами продукта, целью которой является оптимизация технологии (по материалам, процессам, режимам, и т.д.). Ключевых целевых параметров два: качество продукта и качество технологии; и то, и другое надо сделать максимально привлекательным для бизнеса, куда в конечном итоге будет передана технология. Параллельно развертывается работа по масштабированию технологии, переход от лабораторной установки к оборудованию для мелкосерийного производства. Это заказы на специальное оборудование, поиск возможных кандидатов для кооперации усилий, обзор рынка комплектующих с целью максимальной унификации, удешевления оборудования. Ключевых целей тоже две, но уже иные: возможность воспроизводства технологии и ее удешевление. Когда обе задачи решены на достаточном уровне, есть и продукт вполне товарного вида, и прототип промышленного оборудования, и отработанная технология, разворачивается масштабное производство нового продукта.

Лаборатория передает все, что знает и умеет, бизнесу. Вполне возможны еще какие-то упущения и подводные камни при изменении масштаба производства, так что авторское сопровождение технологии не исключено (обе стороны в этом заинтересованы), но цели определяет уже бизнес, а не любопытство исследователя. Производство без сбыта - нонсенс, поэтому проблемы маркетинга, рекламы нового продукта разворачиваются по всем каналам и решаются максимально эффективно (с тщательным подсчетом экономических характеристик мероприятий). Часто этот процесс имеет смысл начинать гораздо раньше, о чем уже вскользь было сказано.

Одной из важнейших услуг производителя новой продукции является послепродажное обслуживание. Это касается и ремонта, и запчастей, и наладки, и многих иных мелочей, которые всплывают иногда только после массовых продаж и претензий пользователей. На этом этапе производитель не всегда в состоянии решить все проблемы, выдвигаемые пользователями, и авторам разработки приходится подключаться для доработки технологии или продукта. Пользователи иногда находят для приобретенного продукта применение, существенно отличающееся от того, которое указано изготовителем в паспортной документации. А это может привести как к нежелательным последствиям, так и к рождению новой полезной функции продукта, а значит, к постановке задачи о его модификации применительно к этой новой функции.

Такова вкратце цепочка событий, вызывающих появление новой технологии и нового продукта. Очевидно, что всю ее невозможно пройти одним и тем же исполнительским составом, так что трансфер, передача знаний и умений при смене команды неизбежны и неоднократны.

В 1911 году американский экономист Й. Шумпетер впервые в явной форме декларировал в качестве основного условия развития общества конкурентное освоение инноваций [6]. Идея Шумпетера сводилась к следующему: 1) изобретательская, инновационная активность по сути своей находится вне экономики, а предприниматели лишь от- 
слеживают появляющиеся открытия и, создавая на их основе изобретения и другие технологические инновации, используют их для получения прибыли; 2) экономическое развитие имеет место через технологические инновации, стараниями предпринимателей вызывающие появление новых продуктов и процессов; 3) инновационный процесс - линейный, начинается с изобретения и заканчивается инновацией, приносящей прибыль. Предложенная линейная модель инновационного процесса означает, что именно инновации, генерируемые независимо и вне экономики и ее нужд, вызывают экономический рост. В пример справедливости этой модели приводился Эдисон, инновационная деятельность которого действительно серьезно изменила экономическую картину мира.

Линейная модель инновационного процесса отделяет, изолирует процесс создания новшества от процесса его освоения и использования обществом и, несмотря на более чем столетний возраст, до сих пор доминирует. Она отражает «ученый снобизм» подавляющего большинства исследователей всех уровней, от теоретиков до разработчиков технологий и производственников. В результате стены многочисленных «башен из слоновой кости», отделяющих творца нового от низких потребностей потребителей этого нового (а непосредственным потребителем интеллектуального продукта каждого этапа цепочки, представленной выше, является не кто иной, как исследователь следующего этапа создания технологий), надежно тормозят процесс экономического развития, оторванный от питающего родника инноваций.

В первой трети XX века созрело понимание, что самотек в экономическом развитии - далеко не оптимальная политика, и государство не может позволить себе устраниться от участия в инновационном процессе, являющемся стержнем развития экономики и общественного благосостояния. Подключение государственной машины к инновационному процессу облегчило и интенсифицировало его на всех стадиях, но не сняло противоречия взаимной изолированности генерации и использования инноваций. Государство и частные инвесторы осуществляли финансовую и политическую поддержку фундаментальной науки, прикладной науки и технологических инноваций по-прежнему изолированно, ориентируясь на текущие нужды преимущественно политического характера. Пристальное изучение всей длинной цепочки перехода от новой фундаментальной идеи до конкретного товарного продукта, подстегивающего экономический рост, привело к выводу, что линейная модель - это только первое приближение к реальной сети взаимосвязей и взаимовлияний субъектов и объектов инновационного процесса, который в действительности является интерактивным практически на всех этапах трансфера технологий. На примере динамики развития инновационной активности в конкретных отраслях стало очевидно, что кроме толкающей силы инноваций, стимулирующих экономический рост, существенную роль играет и тянущая сила спроса, возникающего в обществе в ответ на освоение очередной инновации. Новые возможности генерируют в обществе новые потребности, социальный заказ на новые изобретения.

В результате схема взаимодействия субъектов инновационного процесса становится существенно сложнее, Да и сам процесс рождения и развития инновации оказывается гораздо сложнее, чем представляет это простая линейная модель. Стадий в нем значительно больше, больше и барьеров между этими стадиями, когда для перехода к очередному этапу необходимо прилагать достаточные организационные усилия, которые осуществляют субъекты, доводящие инновации до конечного продукта.

Последовательность событий и действий в цепочке жизненного цикла инновации, описанная ранее, относится к инновационной технологии базисного характера. Последним пунктом цепочки жизненный цикл данного продукта не заканчивается, его история продолжается, но уже со следующими инновациями улучшающего характера, и так вплоть до появления очередной базисной инновации, которая переведет продукт в статус устаревшего.

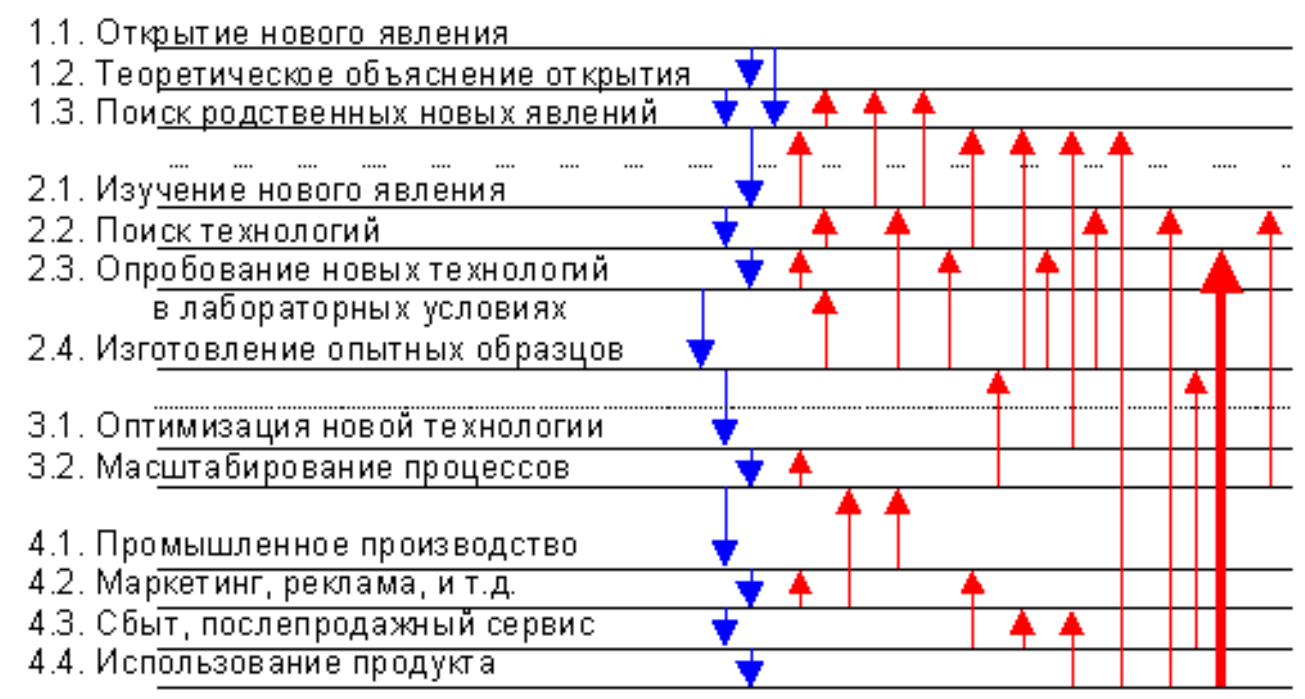

Рисунок 1 - Схема прямых и обратных связей при трансфере технологий [7].

Трансфер технологии, т.е. передача информации об инновации имеет место на каждом переходе от стадии к стадии. Собственно, трансфер необходим объективно, так как в действительности каждая следующая стадия реализуется, как правило, другими людьми, и эта передача, является неотъемлемой частью инновационного процесса. Линей- 
ная модель предполагает однонаправленное продвижение, передачу информации от 1.1 до 4.4. (См. рисунок 1) Однако реально в этой цепочке присутствует множество обратных связей, некоторые из них показаны на схеме.

Прямому процессу трансфера, обозначенному левой цепочкой линий со стрелками вниз, сопутствует и обратный процесс передачи информации от последующих стадий к предыдущим, причем обратных потоков информации гораздо больше, чем видится вначале. Особую роль играет цепь обратной связи, обозначенная более толстой линией: именно она чаще и эффективнее других стимулирует зарождение очередной инновации. Таким образом, экономика, рынок стимулируется инновациями и сам стимулирует инновации.

Схема описывает инновационный процесс от самых его корней, от фундаментальных открытий. На этом этапе тоже есть свои проблемы трансфера и недопонимания, однако, там товара рыночного спроса еще нет, и все проблемы относятся скорее к взаимоотношениям между группами ученых - источников и потребителей информации. В республике, где фундаментальная наука финансируется исключительно государством (и редкими фондами, с которыми ученые по настоящему еще не научились взаимодействовать), этот первый блок инновационного процесса практически не мыслит товарными категориями, так что понятия трансфера и коммерциализации технологий начинают осмысливаться только в начале этапа «прикладные исследования». Вузы только недавно всерьез занялись этой частью науки, академические учреждения до сих пор внутренне сопротивляются, вынужденно принимая программы прикладного характера, основная же масса прикладных исследований велась в отраслевых НИИ и в лабораториях крупных промышленных предприятий. Это - принципиально различные типы исследовательских организаций по уровню подготовки, по организации, по стилю работы, по финансовым и техническим возможностям. Поэтому масштабы и схемы ТТ для этих групп различаются довольно существенно, различаются виды передаваемой информации, относительная роль участников процесса (состав участников тоже имеет свою специфику), высота и характер психологических барьеров на пути ТТ.

Выделяют обычно три основных типа межорганизационного ТТ: 1) передача технологии на стадии НИОКР из научных и исследовательских академических и вузовских организаций в отраслевые или ведомственные лаборатории для доработки и доведения до стадии опытного производства; 2) передача технологии на стадии завершения ОКР из исследовательских организаций в действующие промышленные фирмы для финишного освоения технологии в промышленном масштабе; 3) передача технологии вновь образованным (специально для этой цели) компаниям. Это вовсе не исчерпывающий список, есть еще и четвертый вариант - передача или возврат технологии (часто - не собственно технологии, а технического задания на технологию или исследование) для более глубокого изучения и дальнейшего развития (реализация одной из стрелок, направленных вверх на схеме). Правда, есть сомнение, можно ли считать этот четвертый путь самостоятельным вариантом ТТ, поскольку его можно интерпретировать и как нормальную обратную связь в интерактивной модели ТТ.

Межорганизационный ТТ не исчерпывает всех видов трансфера, кроме него есть еще и межгосударственный ТТ (в нем кроме уже названных трудностей непонимания вступают в этот ряд и языковые, и национальные особенности), и горизонтальный ТТ, когда одна компания в рамках крупного консорциума передает свою готовую технологию другой компании или даже своему филиалу, территориально удаленному от материнской компании. Близко к этому находится и франчайзинг. Но даже межорганизационный ТТ осуществляется в виде необъятного количества вариантов ситуаций, стратегии и тактики этого процесса. Только взаимодействующая пара источник технологии - приемник технологии существует во множестве вариантов. Каждый из двух участников может различаться по типу собственности (государственная организация - частная компания - смешанная компания - общественная организация - частное лицо), по роду деятельности (учебная - научная - производственная - сфера услуг), по размеру (отдельное лицо - малое предприятие - крупная компания - консорциум - государство), по масштабу активности (монотематическая - отраслевая диверсифицированная на несколько отраслей). К разнообразию участников ТТ добавляется не меньшее разнообразие типов передаваемой технологии, разнообразны цели этой передачи, разнообразны третьи лица, без которых ТТ иногда просто неосуществим. Поэтому работа в сфере ТТ - это творчество, это решение задач, каждая из которых нестандартна и неповторима. Но есть типовые приемы и процедуры, типовые ситуации, типовые реакции участников, базовые схемы, наработанная практика успехов и неудач.

Творческая мысль бизнеса довольно быстро нащупала новую оригинальную нишу для деловой активности «интегрированного коня», обслуживающего несколько «трепетных ланей». Эти образования до сих пор именуются по-разному: технопарк, научный парк, научно-технологический парк, технополис, и т.д. Разнообразие наименований отражает разнообразие конкретной направленности их деятельности. Если вернуться к схеме 1, то можно заметить, что три основных смены команды происходят в совершенно разных сферах деятельности: первый разрыв (между этапами 1.3 и 2.1) имеет место в научной среде (фундаментальная наука - прикладная наука), этот разрыв обслуживают организации, носящие, как правило, название научный парк. Второй разрыв (прикладная наука - опытное производство) соответствует контакту научного сообщества с сообществом технологов - и тогда на помощь им приходят научно-технологические парки. Наконец, последний, третий разрыв (опытное производство - промышленность) - это разрыв между разработчиками технологии и эксплуатационниками, масштабным производством, для этого типа контактов характерно содействие технопарков. В действительности, конечно, нет такого четкого соответствия названия и сферы компетентности, скорее название является следствием исторически сложившейся последовательности событий и первоначальным набором клиентов, имевшихся на момент создания соответствующей структуры.

Для успешной коммерциализации процесс трансфера технологий должен опираться на рыночный спрос. И задачи «трансфера» потребностей рынка в научно-техническую сферу успешно решаются посредством инновационных кластеров. Нормативные документы в нашей стране следующим образом определяют цель их создания - «укрепление 
взаимосвязей между участниками кластеров для упрощения доступа к новым технологиям, оптимального распределения рисков, совместного выхода на внешние рынки, организации объединенных научно-исследовательских, опытно-конструкторских и технологических работ, коллективного использования научных знаний и основных средств. Участниками кластера являются: организации, осуществляющие выпуск конечной продукции («ядро» кластера); организации, поставляющие продукцию или оказывающие услуги (аудиторские, консалтинговые, кредитные, страховые, лизинговые, логистические, торговые, операции с недвижимостью) организациям, осуществляющим выпуск конечной продукции; обслуживающие организации (транспортная, инженерная, социальная инфраструктура); научно-исследовательские организации и учреждения образования; организации по поддержке малого и среднего предпринимательства (бизнес-инкубаторы, технопарки, промышленные парки, венчурные фонды, центры трансфера технологий, центры и агентства по развитию предпринимательства, инвестиционные фонды, фонды поддержки предпринимательства, фонды содействия кредитованию (гарантийные фонды, фонды поручительств) и другие» [8]. Государственная программа инновационного развития Республики Беларусь на 2011-2015 годы, утвержденная постановлением Совмина от 26.05.2011 № 669, предполагает создание в стране 6 промышленных кластеров. В ІТ-кластере основой станут частные компании - резиденты ПВТ, в остальных случаях — государственные предприятия-гиганты. Ядром химического кластера в Гродно должны стать ГродноАзот и ГродноХимволокно, нефтехимического в Новополоцке - Нафтан, агромашиностроительного в Гомеле - Гомсельмаш, автотракторостроительного в Минске - МТ3, МАЗ и ММЗ, химико-текстильного в Могилеве - Могилевхимволокно и Моготекс. Кроме того, в республике должен быть создан новый кластер в области нано- и биотехнологий «БелБиоград», который в Минэкономики называют вторым по масштабности после АЭС проектом Беларуси [8]. Создание двух кластеров (фармацевтического и по производству льна) предполагает Стратегия привлечения прямых иностранных инвестиций в Республику Беларусь на период до 2015 года, утвержденная совместным постановлением Совмина и Нацбанка от 18.01 .2012 № $51 / 2[9]$.

В кластерах, в отличие от научных парков, технопарков, технополисов, ядром являются не научные организации, а деловые предприятия. Он включает в себя больше частей цепочки ценности, чем другие формы ТТ. Инновационный кластер пересекается с инновационной системой в части инновационной инфраструктуры и отличается от неё в части результатов деятельности кластера. Результатом деятельности инновационного кластера являются инновационные товары и услуги, а результатом деятельности инновационной системы могут быть патенты, опытные образцы продукции, кадры для предприятий и организаций, обслуживающие несколько кластеров. Развитие инновационных кластеров призвано оптимизировать положение отечественных предприятий в производственных цепочках создания стоимости, содействуя повышению степени переработки добываемого сырья, замещению импорта и росту локализации сборочных производств, повышению уровня неценовой конкурентоспособности отечественных товаров и услуг.

Инновационный кластер отличается и от стратегического альянса. Кластер может быть как отраслевым, так и территориальным образованием. Альянсы чаще всего - структуры отраслевые. Но главное отличие состоит в степени формализации взаимодействий. В альянсе отношения участников имеют определенную, в том числе юридическую форму. В рамках кластера неформальные взаимодействия играют не меньшую роль, чем оформленные, а прирост дохода (рента) достигается за счет эффекта синергии. Горизонтальный ТТ, цепь обратных связей в ТТ, рыночная направленность ТТ находят в кластерных образованиях более адекватный их сути инструментарий.

Бизнес аспект в функционировании инновационных кластеров особенно актуален для стран с транзитивной экономикой, так как слабые искаженные сигналы формирующегося рынка с трудом передаются по каналам обратной связи ТТ разработчикам технологий и фундаментальной науке. Организация трансфера технологий в странах с транзитивной экономикой определяется их положением в мировой технологической пирамиде. Наверху технологической пирамиды находится очень небольшая группа стран (США, Япония и пять-шесть ведущих европейских государств). Следующий уровень - это страны - кандидаты на повышение в технологическом статусе (Китай, азиатские «драконы», еще с полдюжины европейских стран, с некоторыми оговорками Индия и Бразилия). Третий слой - пара десятков неопределившихся стран (по всей видимости, Россию следует отнести именно к этой категории) и, наконец, внизу - все остальные (в том числе Беларусь), коих можно назвать группой стран, не имеющих реальных шансов на технологический апгрейд, или группой чистых акцепторов второсортных технологий.

Количественно процесс международного движения новых технологий отслеживается в экономических обзорах ОЭСР для 34 входящих в ее состав развитых стран и успешных переходных экономик ЕС, где соответствующая информация приводится в виде технологического платежного баланса (ТПБ). Он объединяет международные финансовые потоки технологических платежей и поступлений и в отличие от других статистических показателей, характеризующих науку и инновации, является уникальным инструментом денежной оценки реального участия стран в международном трансфере новых технологий (МТНТ), поскольку отражает платежи за уже готовые для использования новые технологии. Белорусские исследователи провели анализ технологического платежного баланса и показали, что наша страна в мировой технологической пирамиде занимает место чистого акцептора технологий с незначительным потенциалом технологической ренты [10]. Это же исследование выявило ряд стран с транзитивными экономиками, занимающими существенно иные позиции. В группу нетто-экспортеров новых технологий вошла только одна страна с переходной экономикой - Эстония. Это связано с размещением здесь крупными скандинавскими производителями субконтрактных производств в области телекоммуникации и связи. Их продукция составляет более трети эстонского экспорта, а при ее производстве в полном объеме был задействован МТНТ.

Переходные экономики группы ряда стран с дефицитом ТПБ достигли ощутимых успехов в технологическом развитии и к настоящему времени демонстрируют хорошую динамику наращивания потоков международного трансфера новых технологий. Высокотехнологичный экспорт и импорт Чехии вырос по сравнению с 2000 г. в 26 и 14 раз 
соответственно. Достаточно динамичный рост демонстрировал технологический экспорт и импорт Венгрии и Словении (в среднем их объемы выросли в $4-5$ раз). Основой этого явилось расширенное сотрудничество с ТНК развитых стран с опорой на прямые иностранные инвестиции (ПИИ), что позволило встроиться в международные производственные цепочки ТНК, используя, развивая и адаптируя новые технологии, совершенствуя их с учетом требования рынков на основе создания так называемых обогащенных центров производства. Они включают в себя не только производственные линии и цеха, но и собственные исследовательские центры, проводящие научные и опытноконструкторские разработки. Тем самым для других переходных экономик были обозначены ориентиры успешной экономической политики по привлечению ПИИ и освоению мировых научно-технических достижений для повышения технологического уровня производства и конкурентоспособности экономик на основе ТТ.

\section{ВЫВОДЫ}

Трансфер технологий является экономическим ресурсом, источником увеличения ценности при организации экономической деятельности в формах, адекватных его природе. Специфика трансфера технологий как экономического ресурса состоит в особенностях предмета трансфера - технологий, имеющих товарную и нетоварную составляющую (явное и неявное знание), особенностях субъектов ТТ, предполагающих как минимум трехкратную полную смену команд доноров и реципиентов технологий, особенных формах трансфера, из которых наиболее предпочтительным для республики является инновационный кластер, включающий в себя больше частей цепочки ценности, чем другие формы ТТ. Международный трансфер технологий в республике, занимающей в мировой технологической пирамиде положение чистого акцептора технологий с незначительным потенциалом технологической ренты, обеспечивает наилучший результат при расширенном сотрудничестве с транснациональными корпорациями с опорой на прямые иностранные инвестиции, в рамках которого страны с транзитивной экономикой не только получают и используют, но и развивают новые технологии с учетом требования рынка на основе создания так называемых обогащенных центров производства.

\section{ЛИТЕРАТУРА}

1. Юрик В., Юрик С. Международный трансфер новых технологий в переходных экономиках/ В. Юрик, С. Юрик // Банковский вестник. - Февраль 2013. - № 4/585. - С. 16 -25. - С. 16.

2. Юрик В., Юрик С. Международный трансфер новых технологий в переходных экономиках/ В. Юрик, С. Юрик // Банковский вестник. - Февраль 2013. - № 4/585. - С. 16 -25. - С. 17.

3. Бертош Е.В. Международный трансфер технологий в экономическом развитии стран: автореферат диссертации на соискание ученой степени кандидата экономических наук по специальности 08.00.14 — мировая экономика: 30.05.13/ Е.В. Бертош; Белорус. гос. ун-т. - Минск, 2013. - 25 с. - С.8.

4. Медовников Д., Оганесян Т. Неявное знание строителей пирамиды/ Д. Медовников, Т. Оганесян//Эксперт - 26 марта 2012. - №12 (795). [Электронный ресурс] - Режим доступа: http://m.expert.ru/expert/2012/12 Дата доступа: 08. 10. 2014.

5. Белоусенко, М. В. Общая теория экономической организации: организационная эволюция индустриальной экономики / М.Белоусенко // Донецк: ДонНТУ, 2006. - 432 с. $455 \mathrm{c}$.

6. Шумпетер Й. Теория экономического развития/ Й. Шумпетер // Москва: Директмедиа Паблишинг, 2008. -

7. Титов В.В. Трансфер технологий. Учебное пособие для заочного курса «Технологический менеджмент»/ В.В. Титов// [Электронный ресурс] - Режим доступа: http://www.metodolog.ru Дата доступа: 12. 10. 2014.

8. Государственная программа инновационного развития Республики Беларусь на 2011-2015 годы. [Электрон-

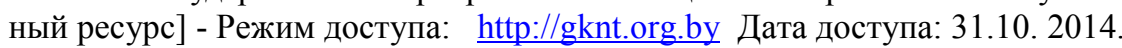

9. Стратегия привлечения прямых иностранных инвестиций в Республику Беларусь на период до 2015 года. [Электронный ресурс] - Режим доступа: http://pravo.by Дата доступа: 12.11. 2014.

10. Юрик В., Юрик С. Международный трансфер новых технологий в переходных экономиках/ В. Юрик, С. Юрик // Банковский вестник. - Февраль 2013. - № 4/585. - С. 16 -25. - С. 18.

Статья поступила в редакцию 9 июня 2015 года. 